\title{
artigo
}

Costa, L.F.; Medeiros, R.J.; Paungartner, L.M.; Luft, T.D.; Santos, A.P.; Paiva, T.S.; Fernandes, M.T.C.

Fatores psicossociais envolvidos na adesão ao tratamento do HIV/AIDS em adultos: revisão integrativa da literatura

\section{Fatores psicossociais envolvidos na adesão ao tratamento do HIV/AIDS em adultos: revisão integrativa da literatura}

Psychosocial factors involved in adherence to the treatment of HIV / AIDS in adults: integrative literature review Factores psicosociales implicados en la adherencia al tratamiento del VIH / SIDA en adultos: revisión integrativa de la literatura

\section{RESUMO}

Objetivo: identificar na literatura os fatores psicossociais envolvidos na adesão ao tratamento do HIV/AIDS em pacientes adultos. Método: trata-se de uma revisão integrativa da literatura utilizando as bases de dados SciELO, PubMed e Lilacs e incluídos artigos brasileiros publicados entre 2014 a 2019, seguiu-se a estratégia PICO para identificar os fatores psicossociais associados à adesão ao tratamento do HIV/AIDS em adultos. A busca bibliográfica ocorreu em maio de 2020. Resultados: foram encontrados 118 artigos e após a leitura na íntegra foram selecionados 5 artigos que correspondiam a questão norteadora. Identificou-se os aspectos emocionais, relação social e atenção profissional como influentes fatores psicossociais no processo de adesão ao tratamento medicamentoso do HIV/AIDS em adultos. Conclusões: a representação social do HIV/AIDS está associada a preconceitos culturais que expõe a pessoa a vulnerabilidades emocionais e sociais, afetando sua decisão na adesão terapêutica.

DESCRITORES: Vírus da imunodeficiência humana; Síndrome de imunodeficiência adquirida; Adesão à medicação; Impacto psicossocial.

\section{ABSTRACT}

Objective: identify in the literature the psychosocial factors involved in adhering to the treatment of HIV / AIDS in adult patients. Methods: This is an integrative literature review using the SciELO, PubMed and Lilacs databases and including Brazilian articles published between 2014 to 2019, followed by the PICO strategy to identify the psychosocial factors associated with adherence to HIV / AIDS treatment in adults. The bibliographic search took place in May 2020. Results: 118 articles were found and after reading in full, five articles were selected that corresponded to the guiding question. Emotional aspects, social relationship and professional attention were identified as influential psychosocial factors in the process of adherence to drug treatment of HIV/ AIDS in adults. Conclusions: We conclude that the social representation of HIV / AIDS is associated with cultural prejudices that exposes the person to emotional and social vulnerabilities, affecting their decision regarding therapeutic adherence.

DESCRIPTORS: Human immunodeficiency virus; Acquired immunodeficiency syndrome; Medication adherence; Psychosocial impact.

\section{RESUMEN}

Objetivo: El propósito de esta revisión integradora es identificar en la literatura los factores psicosociales involucrados en la adherencia al tratamiento del VIH / SIDA en pacientes adultos. Métodos: se trata de una revisión integradora de la literatura utilizando las bases de datos SciELO, PubMed y Lilacs e incluyó artículos brasileños publicados entre 2014 y 2019, seguida de la estrategia PICO para identificar los factores psicosociales asociados con la adherencia al tratamiento del VIH / SIDA en adultos. La búsqueda bibliográfica se realizó en mayo de 2020. Resultados: Se encontraron 118 artículos y luego de su lectura completa se seleccionaron 5 artículos que correspondían a la pregunta orientadora. Los aspectos emocionales, la relación social y el cuidado profesional fueron identificados como factores psicosociales influyentes en el proceso de adherencia al tratamiento farmacológico del VIH / SIDA en adultos. Conclusiones: Concluimos que la representación social del VIH / SIDA está asociada a prejuicios culturales que exponen a la persona a vulnerabilidades emocionales y sociales, afectando su decisión sobre la adherencia terapéutica.

DESCRIPTORES: Virus de inmunodeficiencia humana; Síndrome de inmunodeficiencia adquirida; Cumplimiento de la medicación; Impacto psicosocial.

RECEBIDO EM: 13/10/2020 APROVADO EM: 27/10/2020 


\section{Letícia Falkenbach da Costa}

Enfermeira - Residente Multiprofissional em Saúde Comunitária (ULBRA).

ORCID: 0000-0003-1817-6971

\section{Reinaldo de Jesus Medeiros}

Enfermeiro no Hospital de Pronto Socorro de Canoas. Pós Graduação em Urgência e Emergência Faculdade Dom Alberto - em andamento. ORCID: 0000-0003-2677-0540

\section{Luciana Medeiros Paungartner}

Enfermeira - Pós Graduação em UTI Geral e Gestão da Assistência Intensiva ao Paciente Crítico - Instituto Faveni - em andamento. ORCID: 0000-0003-1983-1114

\section{Thainá Dias Luft}

Acadêmica de enfermagem do Centro Universitário Ritter Dos Reis (UNIRITTER).

ORCID: 0000-0002-3690-2546

\section{Amanda Paz Santos}

Acadêmica de Enfermagem, integrante da Liga da ONG Prematuridade.com (LAOPcom), Voluntária na ONG Prematuridade. com, estagiária do estudo COVIDa no PROADI-SUS/ Hospital Moinhos de Vento (RS), Voluntaria no Curso de Extensão - Programa de Pós-graduação em Saúde da Criança da PUCRS.

ORCID: 0000-0002-5460-4390

\section{Tiago Souza Paiva}

Doutorando em Enfermagem UFRGS. Mestre em Ensino na Saúde UFCSPA. Especialista em Saúde da Família. ORCID: 0000-0001-5989-9469

\section{Morgana Thaís Carollo Fernandes}

Enfermeira. Pós-Doutoranda em Saúde da Criança pela Pontifícia Universidade Católica do Rio Grande do Sul (PUCRS). Professora Colaboradora da Residência Multiprofissional em Saúde da Criança e Pesquisadora Associada do Programa de Extensão e Pesquisa em Saúde Urbana, Ambiente e Desigualdades da Universidade Federal do Rio Grande do Sul (UFRGS).

ORCID: 0000-0002-7989-294X

\section{INTRODUÇÃO}

0 vírus da imunodeficiência humana (HIV) atinge a função imunológica prejudicando os sistemas de defesa e impossibilitando a ação natural contra infecções comuns. A doença pode evoluir para a síndrome da imunodeficiência adquirida (AIDS), quando há manifestações graves da doença, como infecções oportunistas, neoplasias e outras patologias que geram danos diretos aos órgãos ${ }^{1,2}$.

De acordo com as estatísticas globais do Programa Conjunto das Nações Unidas sobre HIV/AIDS (UNAIDS) em 2019 haviam 37,9 milhões adultos vivendo com HIV, sendo 1,7 milhão de novas infecçốes e mais de 700 mil mortes relacionadas à AIDS 3 .

Para a OMS existem grupos populacionais vulnerabilizados como as pessoas privadas de liberdade, usuários de álcool e outras drogas, trabalhadoras e trabalhadores do sexo, gays e homens que fazem sexo com homens. Essa parcela da população encontra-se inserida em cenários e contextos sociais que expõem a determinação social da epidemia do HIV/AIDS e de outras infecções sexualmente transmissíveis (ist's). Esses grupos frequentemente precisam romper as barreiras do preconceito para ter acesso ao diagnóstico e possivelmente o tratamento devido ${ }^{2}$.

Apesar do caráter crônico evolutivo, o HIV é potencialmente controlável com o regime terapêutico, o qual é indicado com início imediato para todas as pessoas que vivem com HIV/AIDS (PVHA). ${ }^{2}$ A terapia com antirretroviral (TARV) é capaz de causar a supressão viral prevenindo a progressão para a $\operatorname{AIDS}^{1,2}$.

No Brasil, a TARV é fornecida de forma universal e gratuita pelo Sistema Único de Saúde (SUS) por meio da lei federal nº 9.313 de 1996 que dispóe a Po- lítica de Distribuição de medicamentos do Programa Nacional de IST/AIDS4. Também há no país a constante melhoria dos serviços de atenção especializada (SAE) no SUS e nos protocolos clínicos que englobam também mudanças comportamentais que envolvem aspectos psicológicos, sociais e culturais no processo terapêuticos.

$\mathrm{Na}$ tentativa de combater a epidemia até o ano de 2030, foi estabelecida, em 2015, a meta 909090 que consiste em três pilares: $90 \%$ de todas as pessoas vivendo com HIV saibam; 90\% PVHA recebam a TARV ininterruptamente; $90 \%$ de todas as pessoas em uso de TARV tenham supressão viral ${ }^{6}$.

A meta relacionada à adesão medicamentosa tornou-se um desafio pelas organizações de saúde, visto que, as decisões terapêuticas devem ser corresponsabilizadas, visando a autonomia da PVHA, ofertando o conhecimento suficiente so- 


\section{artigo}

Costa, L.F.; Medeiros, R.J.; Paungartner, L.M.; Luft, T.D.; Santos, A.P.; Paiva, T.S.; Fernandes, M.T.C.

Fatores psicossociais envolvidos na adesão ao tratamento do HIV/AIDS em adultos: revisão integrativa da literatura

bre os benefícios da adesão ao tratamento. No entanto, é essencial que também haja compreensão que existem aspectos psicossociais, riscos e vulnerabilidades envolvidos no momento da decisão de adesão ao tratamento ${ }^{1,6}$.

Estudo brasileiro realizado com 1.784 adultos entre 18 e 76 anos com diagnóstico de HIV constatou que $98,4 \%$ estavam em uso regular da TARV, no qual, $83,4 \%$ atingiram carga viral indetectável nos últimos 12 meses. No entanto, ao se questionar aspectos psicossociais, 75,5\% tiveram necessidade de esconder o diagnóstico da vida social e $47,9 \%$ relataram haver problemas de saúde mental relacionados a vivência com HIV. Quanto às características socioeconômicas, $72,9 \%$ haviam ensino médio ou educação profissionalizante e 46,5\% relataram não conseguir atender suas necessidades básicas de vida ${ }^{7}$.

Apesar das constantes inovações nas estratégias de diagnóstico e ampliação do tratamento nas organizações de saúde com o objetivo de diminuir a incidência da doença e prover maior qualidade de vida às PVHA, ainda permanece o desafio da adesão à TARV, que permeiam aspectos que transcendem a assistência clínica. Nesse sentido, o objetivo desse estudo foi revisar na literatura os fatores psicossociais envolvidos na adesão no tratamento do HIV/AIDS em pacientes adultos.

\section{MÉTODOS}

Trata-se de uma revisão integrativa de literatura seguindo as etapas de determinação do objetivo; estabelecimento da questão de pesquisa; definição dos critérios de inclusão e exclusão das produções; determinação das informações a serem extraídas dos estudos selecionados; avaliação dos estudos incluídos; interpretação dos resultados e síntese do conhecimento. Para a estruturação da pergunta de pesquisa, adotou-se a estratégia PICO, representada por: população $(\mathrm{P})$, interesse $(\mathrm{I})$, comparação $(\mathrm{C})$ e desfecho/outcomes $(\mathrm{O})$, construindo a pergunta norteadora: Quais os fatores (O) psicossociais (I) envolvidos na adesão ao tratamento (C) do HIV/AIDS do paciente adulto $(\mathrm{P})$ ? 8 .

A busca bibliográfica foi realizada em maio de 2020, por meio das bases de dados The Scientific Electronic Library Online (SciELO), PubMed e Literatura Latino-Americana e do Caribe em Ciências da Saúde (Lilacs) por meio da estratégia de busca (hiv) AND (adesão a medicação) AND year cluster: ("2014" OR "2018" OR "2019" OR "2015" OR "2017" OR "2016").

Os critérios de inclusão foram artigos científicos de pesquisas originais brasileiros, publicados entre 2014 a 2019, que apresentassem, nos títulos ou resumos, referências sobre adesão ao uso de antirretrovirais ou à adesão ao tratamento medicamentoso do HIV. Foram definidos como critérios de exclusão foram monografias, teses, dissertações, artigos de revisão, artigos que não correspondiam a temática estudada e/ou à pergunta de pesquisa, que envolviam na amostra gestantes, crianças ou adolescentes.

Para verificar se os artigos atendiam aos critérios de inclusão e exclusão, realizou-se a avaliação obedecendo a ordem: (1) títulos de todos os estudos identificados; (2) resumos dos estudos na fase anterior; (3) leitura completa dos textos selecionados. Após a exclusão dos artigos que não cumpriram com os critérios de inclusão. Todo processo de seleção foi realizado na presença e concordância de dois pesquisadores.

A avaliação dos artigos quanto ao nível de evidência científica, seguiu a classificação por tipo de estudo da Oxford Centre For Evidence-based Medicine conforme o Quadro 1.

\section{RESULTADOS}

Foram identificados 118 artigos a partir na busca nas bases de dados. Após a leitura dos títulos foram selecionados 28 artigos para dos resumos. Destes, 9 artigos foram lidos na íntegra e 4 artigos foram excluídos por não responder à

\section{Quadro 1. Níveis de evidência por tipo de estudo.}

\begin{tabular}{|l|l|}
\hline NE* & \multicolumn{1}{|c|}{ TIPOS DE ESTUDO } \\
\hline 1A & $\begin{array}{l}\text { Revisões sistemáticas e metanálises de ensaios clínicos comparáveis. Estudos controlados randomizados bem delineados com } \\
\text { desfecho clínico relevante. }\end{array}$ \\
\hline 1B & Estudos controlados randomizados com estreito intervalo de confiança. \\
\hline 1C & Resultados do tipo "tudo ou nada". Estudo de série de casos controlados. \\
\hline 2A & Revisão sistemática homogênea de estudos de coorte (com grupos de comparação e controle de variáveis). \\
\hline 2B & Estudo de coorte com pobre qualidade de randomização, controle ou sem acompanhamento longo, estudo de coorte transversal. \\
\hline 2C & Resultados de pesquisas (observação de resultados terapêuticos ou evolução clínica). \\
\hline 3A & Revisão sistemática homogênea de estudos de caso com grupo-controle. \\
\hline 3B & Estudos de caso com grupo-controle. \\
\hline 4 & Relatos de caso e série sem definição de caso controle. \\
\hline 5 & Opinião de autoridades respeitadas ou especialistas. Revisão da literatura não sistemática. \\
\hline Fonte: Adaptado de Oxford Centre Evidence-Based Medicine. Elaborado pelos autores. Legenda**NE-Nivel de Evidência \\
\hline
\end{tabular}


questão norteadora e aos critérios de inclusão. Ao final 5 artigos compuseram o corpus do trabalho. A Figura 1 apresenta o fluxograma de estratégia de seleção dos estudos de acordo com PRISMA ${ }^{10}$.

Para análise e síntese das publicações

\section{Figura 1. Fluxograma de estratégia de seleção de estudos}

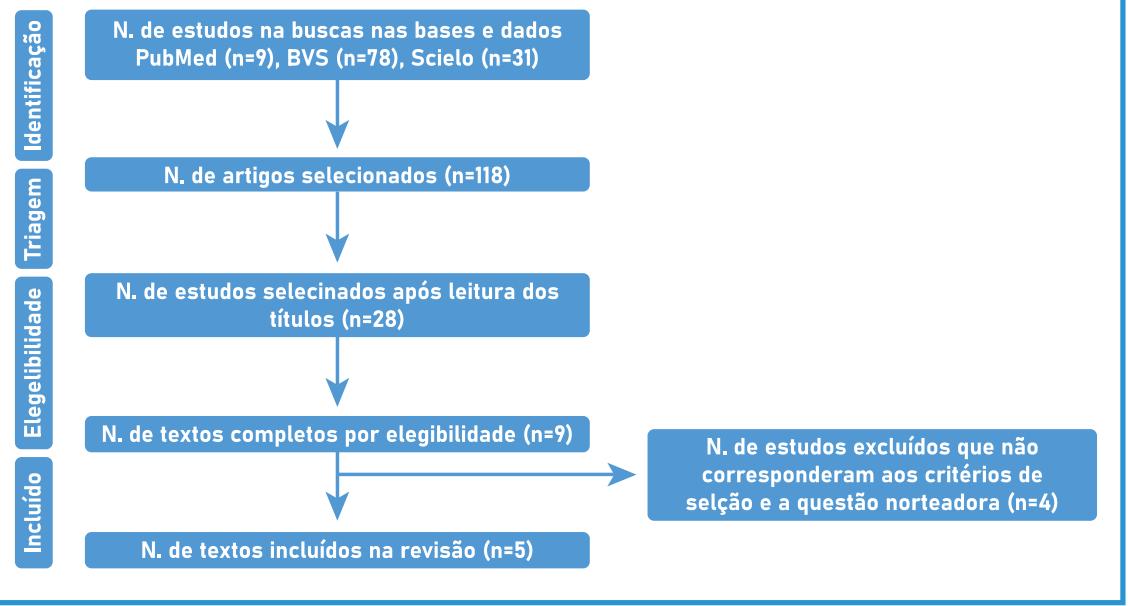

Fonte: Prisma, 2015. Adaptado pelos autores.

\section{Quadro 2. Quadro Sinóptico de Sumarização dos Estudos Incluídos na Revisão Integrativa}

\begin{tabular}{|c|c|c|c|c|c|}
\hline NE & ESTUDO & AUTORES & OBJETIVOS & $\begin{array}{l}\text { AMOSTRA } \\
\text { (N) }\end{array}$ & RESULTADOS \\
\hline $2 C$ & $\begin{array}{l}\text { Avaliação da adesão ao } \\
\text { tratamento antirretrovi- } \\
\text { ral de pessoas vivendo } \\
\text { com HIV. Saúde e pes- } \\
\text { quisa, 2018.11 }\end{array}$ & $\begin{array}{c}\text { Primeira, MR; } \\
\text { Santos, EEP; Züge } \\
\text { SS; Magnano, TSBS; } \\
\text { Paula, CC; Padoin } \\
\text { SMM. }\end{array}$ & $\begin{array}{l}\text { Avaliar a adesão ao } \\
\text { tratamento antirretro- } \\
\text { viral de pessoas que } \\
\text { vivem com HIV através } \\
\text { do "Cuestionario para la } \\
\text { Evaluación de la Adhesi- } \\
\text { ón al Tratamiento Antir- } \\
\text { retroviral" (CEAT-VIH) }\end{array}$ & 179 & $\begin{array}{l}\text { Foi identificado que } 46,4 \% \text { apre- } \\
\text { sentaram grau de adesão baixa ou } \\
\text { insuficiente, } 56,4 \% \text { deixou de fazer uso } \\
\text { da TARV por um ou mais dias, } 79,3 \% \\
\text { deixaram de fazer uso por se sentir } \\
\text { triste ou deprimido. }\end{array}$ \\
\hline $2 A$ & $\begin{array}{c}\text { Interações sociais e } \\
\text { a adesão à terapia } \\
\text { antirretroviral de pessoas } \\
\text { vivendo com HIV/AIDS. } \\
\text { Rev Mineira de Enferm., } \\
2017.12\end{array}$ & $\begin{array}{l}\text { Freitas, MIF; Bonolo, } \\
\text { PF; Miranda, WD; } \\
\text { Guimarães, MDC. }\end{array}$ & $\begin{array}{l}\text { Compreender a influência } \\
\text { das interações sociais na } \\
\text { terapia antirretroviral em } \\
\text { pacientes em início de } \\
\text { tratamento. }\end{array}$ & 30 & $\begin{array}{l}\text { Identificou-se que as relações } \\
\text { familiares, com parceiros e amigos } \\
\text { intimos auxiliam a manutenção } \\
\text { medicamentosa e o apoio profissional } \\
\text { colabora com a continuidade do } \\
\text { tratamento. }\end{array}$ \\
\hline $2 C$ & $\begin{array}{l}\text { Adesão à terapia antirre- } \\
\text { troviral e suas repre- } \\
\text { sentações para pessoas } \\
\text { vivendo com HIV/AIDS. } \\
\text { Esc. Anna Nery, 2014.13 }\end{array}$ & $\begin{array}{l}\text { Paschoal, EP; Santo, } \\
\text { CCE; Gomes, AMT; } \\
\text { Santos, El; Oliveira, } \\
\text { DC; Pontes, APM. }\end{array}$ & $\begin{array}{l}\text { Analisar o processo } \\
\text { de adesão à terapia } \\
\text { antirretroviral e suas } \\
\text { representações sociais } \\
\text { para pessoas que vivem } \\
\text { com HIV/AIDS. }\end{array}$ & 30 & $\begin{array}{l}\text { Como elemento facilitador a adesão } \\
\text { da TARV apoio familiares } 3,4 \% \text {, apoio } \\
\text { e orientação profissional } 9,7 \% \text {. Os } \\
\text { fatores que dificultam o processo de } \\
\text { adesão a TARV como falta de amor } \\
\text { à vida, desinteresse, pensamentos } \\
\text { suicidas, sofrimento fizeram parte de } \\
7,4 \% \text { dos participantes, a necessidade } \\
\text { de esconder socialmente } 4,2 \% \text {. }\end{array}$ \\
\hline
\end{tabular}




\section{artigo}

Costa, L.F.; Medeiros, R.J.; Paungartner, L.M.; Luft, T.D.; Santos, A.P.; Paiva, T.S.; Fernandes, M.T.C.

Fatores psicossociais envolvidos na adesão ao tratamento do HIV/AIDS em adultos: revisão integrativa da literatura

\begin{tabular}{|c|c|c|c|c|c|}
\hline $3 B$ & $\begin{array}{l}\text { Terapia com antirretrovi- } \\
\text { rais: grau de adesão e a } \\
\text { percepção dos indivíduos } \\
\text { com HIV/Aids. Acta Paul } \\
\text { de Enferm., } 2018.14\end{array}$ & $\begin{array}{l}\text { Freitas, JP; Sousa, } \\
\text { LRM; Cruz, MCMA; } \\
\text { Caldeira, NMVP; } \\
\text { Gir E. }\end{array}$ & $\begin{array}{l}\text { Apreender os aspectos } \\
\text { relacionados ao grau } \\
\text { de adesão de pessoas } \\
\text { vivendo com HIV/AIDS } \\
\text { aos antirretrovirais. }\end{array}$ & 40 & $\begin{array}{c}\text { O apoio familiar constitui um aspecto } \\
\text { facilitador para o enfrentamento da } \\
\text { doença e estimulação para a ade- } \\
\text { são medicamentosa. No entanto, } \\
\text { experiências negativas com parcei- } \\
\text { ros íntimos e falta de apoio familiar } \\
\text { impactaram negativamente na adesão } \\
\text { medicamentosa. Condições socioe- } \\
\text { conômicas desfavoráveis para a não } \\
\text { adesão medicamentosa constituiu } \\
18,5 \% \text { dos entrevistados }\end{array}$ \\
\hline 3B & $\begin{array}{l}\text { Será que esse remédio } \\
\text { vai valer a pena mesmo? } \\
\text { Estudo antropológico } \\
\text { sobre a adesão às tera- } \\
\text { pias antirretrovirais entre } \\
\text { grupos de mútua ajuda } \\
\text { de pessoas vivendo com } \\
\text { HIV/aids. Saúde soc., } \\
\text { 2014.15 }\end{array}$ & $\begin{array}{c}\text { Picelli, I; Diaz-Ber- } \\
\text { mudez, XP. }\end{array}$ & $\begin{array}{l}\text { Compreender o funcio- } \\
\text { namento e os poten- } \\
\text { ciais benefícios dessas } \\
\text { tecnologias para a } \\
\text { vivência com o vírus, em } \\
\text { particular para adesão à } \\
\text { medicação antirretroviral }\end{array}$ & 14 & $\begin{array}{l}\text { A ajuda mútua praticada em grupos } \\
\text { terapêuticos auxilia no enfrentamento } \\
\text { da nova condição de saúde e na manu- } \\
\text { tenção do tratamento. }\end{array}$ \\
\hline
\end{tabular}

Quadro 3. Fatores Psicossociais Envolvidos na Adesão ao Tratamento do HIV/ AIDS ao paciente adulto.

\begin{tabular}{|c|c|}
\hline ESTUDOS & FATORES PSICOSSOCIAIS ENVOLVIDOS NA ADESÃO \\
\hline \multirow{7}{*}{$\begin{array}{c}\text { Freitas, MIF et al.; } 2017 \\
\text { Paschoal, EP et al.; } 2014 \\
\text { Freitas, JP et al.; } 2018 \\
\text { Picelli, I et al.; } 2014\end{array}$} & Aspectos Positivos \\
\hline & Apoio familiar e/ou de parceiros \\
\hline & Orientação profissional \\
\hline & Grupos de ajuda mútua \\
\hline & Apoio religioso \\
\hline & Autoestima \\
\hline & Redes sociais de apoio \\
\hline \multirow{10}{*}{$\begin{array}{c}\text { Picelli l; } 2014 \\
\text { Freitas JP; } 2018 \\
\text { Paschoal PE; } 2014 \\
\text { Primeira MR; } 2017\end{array}$} & Aspectos Negativos \\
\hline & Depressão ou tristeza e suicídio \\
\hline & Medo de morrer \\
\hline & Rejeição familiar e/ou de parceiros íntimos e medo de abandono \\
\hline & Condições socioeconômicas desfavoráveis \\
\hline & Carência de apoio emocional \\
\hline & Representação social da terapia antirretroviral \\
\hline & Preconceito \\
\hline & Baixa autoestima \\
\hline & Uso de álcool e outras drogas \\
\hline
\end{tabular}

\section{DISCUSSÃO}

A avaliação do impacto do vírus do HIV na saúde e na qualidade de vida das pessoas tem sido objeto de estudos desde a sua descoberta. Atualmente, com o aumento da expectativa de vida entre pessoas que vivem com a AIDS, a investigação sobre qualidade de vida se tornou mais relevante devido à busca de instrumentos de avaliação de saúde mais abrangentes, ou seja, que envolvam fatores psicológicos, sociais e estruturais ${ }^{16}$. Este estudo reforçou que a representação social do HIV/AIDS está associada a preconceitos culturais que expõe a PVHA a vulnerabilidades emocionais e sociais, afetando sua decisão na adesão terapêutica.

O suporte emocional pode representar a segurança de que há pessoas a quem o usuário pode recorrer quando necessitar, consiste em comportamentos como ouvir e escutar ou fazer companhia, o que contribui para que a pessoa se sinta cuidada e/ou estimada, seja no meio familiar e social, nos serviços de saúde, o que também colabora para o manejo e adesão ao tratamento ${ }^{12-15}$.

Um estudo transversal realizado no Paraná, avaliou que quando as PVHIV recebem apoio emocional as chances de adesão aumentam em até $7,9 \%$, o estudo sugere que quanto maior o apoio emocional, melhor a adesão ao tratamento e, consequentemente, menor a carga viral $^{17}$. Para Freitas e autores (2018), o suporte emocional familiar para enfrentamento da nova condição é relevante em diferentes momentos da vida das PVHA, tanto para a aceitação do diagnóstico quanto na percepção da necessidade de iniciar o tratamento e conduzi-lo de forma consistente ${ }^{14}$. 
Uma pesquisa realizada na Paraíba, evidenciou que $58 \%$ dos participantes (36), que realizaram acompanhamento psicológico tiveram comportamento de adesão tardio ao tratamento, evidenciando que estes indivíduos necessitam de acompanhamento profissional psicológico para realizar uma futura adesão à TARV18.O medo, a discriminação e a rejeição social são consideradas uma barreira para os adultos jovens que vivem com $\mathrm{HIV} / \mathrm{aids}^{19}$.

O constante receio de exposição pública e rejeição social coloca a PVHA em sofrimento psíquico, fazendo que tenha atitudes cautelosas tais como: abandonar o tratamento, esconder a condição e/ou a medicação, abandonar o tratamento medicamentoso por poder chamar atenção e porque algumas necessitam ser armazenadas na geladeira, o que prejudicam seu tratamento ${ }^{13}$. Em relação à confidência do diagnóstico da soropositividade, um estudo mostrou que $51,3 \%$ (119) dos participantes mantêm a informação em segredo ou contaram para no máximo cinco pessoas ${ }^{17}$.

Por vezes, veem como necessidade de reorganização social de forma limitada para expor o progresso terapêutico a amigos e parceiros íntimos de confiança. Neste sentido, uma rede de apoio fragilizada ou até rompida, prejudica a adaptação terapêutica na rotina do indivíduo e da família, e oferece maior risco sentimentos emocionais negativos, gerando a ideia da inevitável solidão e a falta de sentido de continuar o tratamento medicamentoso.

Em uma pesquisa realizada no Sul do Brasil, os adultos jovens expressaram experiências negativas de estigma e discriminação quando revelado seu diagnóstico para alguns colegas e familiares. E, por isso, a aceitação do diagnóstico nem sempre ocorre por parte dos adultos jovens, porém mesmo diante dos abalos emocionais e psicológicos advindos do enfrentamento do diagnóstico os mesmos demonstraram preocupação com seu tratamento, por estar relacionado com o prolongamento e qualidade de vida ${ }^{19}$.

A participação da família na rotina terapêutica mostrou-se um dos principais
Primeira MR e colaboradores

(2018) sugere o

investimento na

atenção aos aspectos

psicossociais,

envolvendo a rede

de apoio social

desta população,

uma vez que, tem

papel fundamental

em amenizar as

consequências de

eventos estressantes,

o apoio insuficiente

do meio social e

familiar parece

afetar negativamente

a adesão,

encaminhando o

paciente à depressão

e à desesperança. fatores que impactam positivamente na decisão da adesão à medicação. $\mathrm{O}$ apoio familiar contribui na retomada medicamentosa, a superação de dificuldades relacionadas ao tratamento e fortalece o vínculo afetivo. No entanto, pode haver atitudes negativas pelos familiares e/ou companheiros por conta do conhecimento limitado e acompanhado de preconceitos sociais que causam sofrimento emocional que favorecem o abandono medicamentoso $^{11-15,19}$.

Além disso, por mais que o acesso ao tratamento seja gratuito no Brasil, o déficit de renda pode ser uma barreira para a satisfação com o suporte social percebido, a precariedade econômica pode impactar negativamente no acesso aos serviços de saúde, por exemplo, quando as PVHIV precisam se deslocar de suas cidades para ter acesso aos serviços especializados localizados em municípios de maior porte19,20-21.Dificuldade está também foi identificada no estudo de Freitas e autores $(2018)^{14}$.

Primeira MR e colaboradores (2018) sugere o investimento na atenção aos aspectos psicossociais, envolvendo a rede de apoio social desta população, uma vez que, tem papel fundamental em amenizar as consequências de eventos estressantes, $o$ apoio insuficiente do meio social e familiar parece afetar negativamente a adesão, encaminhando o paciente à depressão e à desesperança.

O incentivo pelo profissional de saúde também foi um aspecto facilitador na adesão ao tratamento ${ }^{11-15}$. Pacientes frequentemente se abrem para os profissionais e pode-se dizer que a adesão à terapia antirretroviral é positivamente influenciada pelas interaçóes com o cuidado ofertado pelos profissionais como base para se sentirem seguros ${ }^{12}$. Diante um diagnóstico ou condições clínicas envolvidas, o profissional deve considerar o sofrimento emocional que pode gerar para o indivíduo e para a família, sendo necessária uma atenção especializada que favoreça o vínculo entre o usuário e o serviço de saúde. A escuta ativa praticada na assistência é capaz de identificar o contexto no qual a PVHA está inse- 
rida, facilitando a formulação de um plano terapêutico individual e a readequação da rotina, diminuindo os riscos de fragilidade psicossocial $^{12}$.

Um estudo mostrou que médicos e enfermeiros são os principais estimuladores para adesão a terapia medicamentosa ${ }^{13}$. Uma vez que o médico atua com a sua formação de caráter curativo e o enfermeiro, é formado para cuidar por meio da educação em saúde, escuta ativa e prevenção ${ }^{22}$. Os serviços de saúde são essenciais para adesão ao tratamento para elaborar estratégias como: estudo de casos, oficinas interdisciplinares e grupos de adesão que têm como objetivo melhorar a aderência ao tratamento por acolher o paciente e levá-lo a ser o principal sujeito deste processo de mudança ${ }^{13}$. Uma pesquisa realizada em Brasília com 99 voluntários demonstrou uma boa/adequada adesão ao tratamento ao HIV com $75 \%$ dos voluntários, e $87 \%$ dos entrevistados tinham uma boa relação com o médico ${ }^{23}$.

Grupos são uma alternativa de produção de saúde, reforçando uma rede de suporte que se articula com as orientaçóes obtidas nos serviços de saúde, em um estudo identificou que os grupos incentivam a manutenção do comprometimento com a medicação da PVHIV, além de que as pessoas que frequentam grupos de mútua ajuda têm conseguido se encorajar para retomar trajetórias profissionais ${ }^{15}$.

Uma das atribuições da Estratégia de Saúde da Família (ESF), porta de entrada para os usuários, é realizar ações de educação em saúde para a prevenção de agravos e promoção da saúde na área de abrangência de cada equipe, que corresponde, também, ao território da escola,
As representações psicossociais das PVHIV estão

presentes como

aspectos que

estimulam, mas

que também

podem significar

impedimentos à

adesão à TARV.

Interações familiares

e sociais, são as

interações mais

importantes para o

processo de aceitação

do tratamento de

pessoas vivendo com

o HIV e AIDS. lugar onde pode ser realizada ações educativas por meio do Programa Saúde na Escola (PSE) 1,24. No estudo qualitativo de Paiva e autores, foi analisado o planejamento das práticas educativas para a prevenção do HIV/AIDS realizadas com estudantes de uma escola pública da região sul, os autores sugerem que as ações devam oportunizar espaços para reflexão e crítica do assunto, colaborando a formação da consciência do escolar, assim rompendo o modelo clínico tradicional de educação ${ }^{25}$.

Esses achados reforçam a necessidade de um cuidado integral e multiprofissional, de forma que os pacientes se sintam apoiados em suas dificuldades. A assistência ofertada pelos profissionais é um fator importante da adesão ao tratamento, especialmente no início, quando os pacientes têm que enfrentar barreiras psicossociais.

\section{CONCLUSÃO}

As representações psicossociais das PVHIV estão presentes como aspectos que estimulam, mas que também podem significar impedimentos à adesão à TARV. Interações familiares e sociais, são as interações mais importantes para o processo de aceitação do tratamento de pessoas vivendo com o HIV e AIDS.

Os resultados também revelaram a necessidade de que profissionais de saúde entendam as representações sobre HIV/ AIDS, especialmente em relação à importância da representatividade das relações sociais do paciente. A evidência mostra que o medo da discriminação apresenta risco para a adesão ao tratamento antirretroviral.

\section{REFERÊNCIAS}

1. Brasil. Ministério da Saúde. Secretaria de Vigilância em Saúde. Departamento de Vigilância, Prevenção e Controle das Infecções Sexualmente Transmissiveis, do HIV/Aids e das Hepatites Virais. Protocolo Clínico e Diretrizes Terapêuticas para Manejo da Infecção pelo HIV em Adultos. $1^{\circ}$ Ed. Brasília (DF): Ministério da Saúde, 2018. 412p;
2. Brasil. Organização Pan-Americana da Saúde (OPAS). [Internet]. Folha informativa - HIV/Aids.2017.Disponivel em: https:// www.paho.org/bra/index.php?option=com_content\&view=article\&id=5666: folha-informativa-hiv-aids\&Itemid=812;

3. UNAIDS. Programa Conjunto das Nações Unidas sobre HIV/ Aids. [Internet]. Resumo Informativo - Estatísticas Mun- 


\section{REFERÊNCIAS}

diais Sobre o HIV.2020. Disponivel em: https://unaids.org br/wp-content/uploads/2020/07/2020_07_05_UNAIDS_ GR2020_FactSheet_PORT-final-1.pdf;

4. Brasil. Lei n 9.313, de 13 de novembro de 1996. Ministério da Saúde. Diário Oficial da União 14 de Novembro de 1996.

5. Brasil. Ministério da Saúde. Secretaria de Vigilância em Saúde. Programa Nacional de DST e Aids. Manual de adesão ao tratamento para pessoas vivendo com HIV e Aids. $1^{\circ}$ Ed.Brasília (DF): Ministério da Saúde, 2008.130 p.

6. UNAIDS. Programa Conjunto das Nações Unidas sobre HIV/ Aids. 90-90-90 Uma meta ambiciosa de tratamento para contribuir para o fim da epidemia de AIDS. Genebra, Suiça; 2015. 38 p.

7. BRASIL. Sumário Executivo: Índice de Estigma em relação às pessoas vivendo com HIV/AIDS BRASIL. 2019. 92p.

8. Santos C, Pimenta C, Nobre M. A estratégia PICO para a construção da pergunta de pesquisa e busca de evidências. Rev. lat.-am. enferm. [Internet]. 2007;15(3):508-11. Disponível em: <http://www.revistas.usp.br/rlae/article/view/2463>

9. Oxford Centre for Evidence-Based Medicine. Levels of evidence [Internet] 2009. Disponivel em: http://www.cebm.net/oxfordcentre-evidence-based-medicine-levels-evidencemarch-2009/

10. Galvão TF, Pansani TSA, Harrad D. Principais itens para relatar Revisões sistemáticas e Meta-análises: A recomendação PRISMA. Epidemiologia e Serviços de Saúde [internet]. 2015 [citado em 10 jun jul 2020;24(2):335-342. doi: https://doi. org/10.5123/S1679-49742015000200017

11. Primeira MR, Santos DPEE, Züge SS, Magnano SDST, Paula CC, Padoin MDMS. Avaliação da adesão ao tratamento antirretroviral de pessoas vivendo com HIV. Saúde e Pesquisa, Maringá (PR) [internet]. 2018 [citado em 05 mai jul 2020]; 11(2):307-314. Doi: http://dx.doi.org/10.17765/19831870.2018v11n2p307-314

12. Freitas FDIM, Bonolo FDP, Miranda DDW, Guimarães CDM. Interações sociais e a adesão à terapia antirretroviral de pessoas vivendo com HIV/AIDS. Rev Mineira de Enferm [internet]. 2017 [citado em 05 mai jul 2020];21:e-1001. doi: http://www. dx.doi.org/10.5935/1415-2762.20170011

13. Paschoal PE, Santo EDCC, Gomes TMA, Santos DIE, Oliveira DCD, Pontes DMPA. Adesão à terapia antirretroviral e suas representações para pessoas vivendo com HIV/AIDS. Esc. Anna Nery [internet]. 2014 [citado em 05 mai jul 2020];18(1):32-40. doi: https://doi.org/10.5935/1414-8145.20140005.

14. Freitas, JP; Sousa, LRM; Cruz, MCMA; Caldeira, NMVP; Gir E. Terapia com antirretrovirais: grau de adesão e a percepção dos indivíduos com HIV/Aids. Acta Paul de Enferm [internet]. 2018 [citado em 05 mai jul 2020];31(3):327-333. doi: https:// doi.org/10.1590/1982-0194201800046.

15. Picelli I, Díaz-Bermúdez XP. Será que esse remédio vai valer a pena mesmo? Estudo antropológico sobre a adesão às terapias antirretrovirais entre grupos de mútua ajuda de pessoas vivendo com HIV/aids. Saude soc [Internet]. 2014 [citado em
05 mai jul 2020];23(2):496-509. doi: http://dx.doi.org/10.1590/ S0104-12902014000200011.

16. Medeiros B, Silva J, Saldanha AAW. Determinantes biopsicossociais que predizem qualidade de vida em pessoas que vivem com HIV/AIDS. Estudos de Psicologia [Internet]. 2013 [citado em 04 jul 2020];18(4):543-550. Disponivel em: https:// www.redalyc.org/articulo.oa?id=26130639001

17. Lenzi L, Tonin FS, Souza VR, Pontarolo R. Suporte Social e HIV: Relações Entre Características Clínicas, Sociodemográficas e Adesão ao Tratamento. Psicologia: Teoria e Pesquisa, (2018). 34, e34422. Doi: https://doi.org/10.1590/0102.3772e34422

18. Ferreira MAM, Lima TNB, Rodrigues BFL, Nascimento JA, Bezerra VP, Patrício ACF. Conhecimento e fatores que influenciam na adesão à terapia antirretroviral de pessoas vivendo com HIV/Aids. Cogitare enferm. [Internet]. 2020 [citado em 04 jul 2020];25. doi: http:// dx.doi.org/10.5380/ce.v25i0.67768

19. Costa VT, Meirelles BHS. Adesão ao tratamento dos adultos jovens vivendo com HIV/AIDS sob a ótica do pensamento complexo. Texto contexto - enferm. [Internet]. 2019 [citado em 04 set 2020];28:e20170016. https://doi.org/10.1590/1980265x-tce-2017-0016.

20. Silva OR, Primeira MR, Santos WM, Cardoso PC, Mello PSM. Associação entre suporte social com adesão ao tratamento antirretroviral em pessoas vivendo com o HIV. Rev. Gaúcha Enferm. [Internet]. 2020 [citado em 05 set 2020];41:e20190290. Doi: https://doi.org/10.1590/1983-1447.2020.20190290.

21. Silva JAG, Dourado I, Brito AM, Silva CAL. Fatores associados à não adesão aos antirretrovirais em adultos com AIDS nos seis primeiros meses da terapia em Salvador, Bahia, Brasil. Cad. Saúde Pública [Internet]. 2015 [citado em 05 jul 2020];31(6):1188-1198. doi: https://doi.org/10.1590/0102$311 \times 00106914$.

22. Nogueira VPF, Gomes AMT, Machado YY, Oliveira DC. Cuidado em saúde à pessoa vivendo com HIV/AIDS: representações sociais de enfermeiros e médicos. Rev enferm UERJ [internet]. 2015 [citado em 07 jul 2020];23(3):331-7. doi: http://dx.doi. org/10.12957/reuerj.2015.14466.

23. Souza HC, Mota MR, Alves AR, Lima FD, Chaves SN, Dantas RAE, et al. Análise da adesão ao tratamento com antirretrovirais em pacientes com HIV/AIDS. Revista Brasileira de Enfermagem [internet]. 2019 [citado em 07 jul 2020];72(5):12951303. doi: https://dx.doi.org/10.1590/0034-7167-2018-0115

24. Melo EA, Maksud I, Agostini R. Cuidado, HIV/Aids e atenção primária no Brasil: desafio para a atenção no Sistema Único de Saúde. Revista Panamericana de Salud Pública [internet]. 2018 [citado em 07 jul. 2020];42:151. doi: https://doi.org/10.26633/ RPSP.2018.151

25. Paiva TS, Costa MR, Fernandes MTC, Alves CN, Silveira LMOB. O paradoxo do planejamento das ações para a prevenção do HIV/AIDS em uma escola pública. REFACS [Internet]. 2020 [citado em 08 jul 2020];8(1):18-26. doi: 10.18554/refacs. v8i1.4453 